\title{
Autologous Tumor Infiltrating Lymphocytes LN-144
}

National Cancer Institute

\section{Source}

National Cancer Institute. Autologous Tumor Infiltrating Lymphocytes LN-144. NCI

Thesaurus. Code C120552.

A preparation of autologous tumor infiltrating lymphocytes (TILs), with potential antineoplastic activity. TILs are isolated from a patient's tumor tissue, cultured in vitro with high-dose interleukin-2 (IL-2), further selected based on antigen specificity and tumor reactivity, and the selected TILs are subsequently expanded. Upon re-introduction of LN-144 into the patient, the TILs re-infiltrate the tumor, specifically recognize the tumor-associated antigens (TAAs), and initiate tumor cell lysis. IL-2 induces the proliferation and expansion of TILS in vitro. 